\title{
INFLUENCIAS INCASICAS EN LA PREHISTORIA CHILENA
}

\author{
Greta Mostny \\ (Universidad de Chile)
}

La influencia política y cultural del Imperio incásico sobre las entonces existentes civilizaciones chilenas ha sido siempre campo de controversias, mientras que los autores del siglo pasado eran partidarios, de que la gran mayoría de las manifestaciones culturales, en lo que hoy es la República de Chile, se debía únicamente a las influencias llegadas del Perú a través de las conquistas de los Incas, se dejó sentir más tarde otra corriente de opinión, representada ante todo por Ricardo Latcham, de que las influencias del imperio incásico eran altamente sobreestimadas y que se sobrepusieron solamente como última y tardía capa sobre las civilizaciones existentes con anterioridad. Este último autor, precedido en sus estudios por $\mathrm{M}$. Uhle, comprobó, gracias a su infatigable labor de explorador de los yacimientos arqueológicos, que las provincias del Norte \& Centro de Chile estaban ocupadas por pueblos agricultores, que habian desarrollado sus propias culturas y ejercían todas las industrias propias"a su ambiente geográfico dentro del área cultural andina, correspondiendo a cada fase formas típicas y capaces de desarrollarse. Cuando, en la segunda mitad del siglo XV, bajo el reinado de Tupac Yupanqui, los ejércitos incásicos ocuparon el Norte y Centro de Chile - probablemente hasta el río Maule- se encontraron con una población sedentaria, en posesión de todos los básicos adelantos culturales típicos del área ocupada por ellos, y al mismo tiempo bastante vigorosa para incorporar las influencias recibidas y transformarlas en algo que expresaba tanto el espíritu de los conquistados como el de los conquistadores.

Un ejemplo típico de esta capacidad de los indios chilenos de entonces, nos ofrece un cementerio encontrado en la vecindad de Santiago de Chile, hace pocos años.

Al este de la capital, donde las últimas casas del elegante suburbio de "La Reina" ya escalan los primeros estribos de la Cordillera de los Andes, se encontró en una pequeña quebrada, una serie de tumbas no violadas. La primera, excavada por los trabajadores, que la habían descubierto, dió la pista y pudimos después excavar con todo cuidado cuatro más. Todas ellas eran parecidas en su plan: una cámara subterránea, a la cual conducía un túnel inclinado desde la superficie. Dos 
de ellas tenian un nicho o cámara secundaria cada una, e igualmente dos ienían un pique que comunicaba la parte subteránea con la superficie. Según el largo y la inclinación del túnel, este tenía el piso labrado en peldaños. En todos los casos la desembocadura del túnel de acceso en la cámara subterránea estaba tapado con un muro de piedras y tado el pasillo estaba rellenado.con tierra, mientras que la cámara queciaba libre de relleno. Entre las piedras que tapaban la entrada del pasilīo en la superficie, se encontró un vaso de greda, mientras que las demás piezas del ajuar fúnebre estaban depositadas en la cámara alredecior del esqueleto. Las dimensiones de las cámaras subterráneas varia. ban entre 1,6 por $2,2 \mathrm{~m}$ y 2,2 por $3,2 \mathrm{~m}$ de diámetro, siendo su forma ova. iada. Los pasillos tenían entre 1,6 y $3,2 \mathrm{~m}$ de largo y la altura de la bóveda oscilaba entre 1,4 y $1,9 \mathrm{~m}$, mientras que la altura del pasillo o túnel era entre 0,7 y $1,2 \mathrm{~m}$.

En cada tumba había un esqueleto en Ia cámara principal (salvo una excepción) y otro en la secundaria. En todos los casos los esqueletos estaban de espaldas y tendidos. Unicamente en el pique de la tercera tumba se encontró el esqueleto de un niño de corta edad, en posición acuclillada y cabeza abajo. El ajuar, que consistía ante todo en reramios de diferentes formas y en ququénidos, se encontraba alrededor del esqualeto o dispuesto a lo largo de las paredes de la cámara. En dos instancias, el esqueleto había sido encontrado entre dos palos de madera, como si el cadáver hubiera sido depositado en una camilla. cementerio.

Estos, en pocas palabras, eran los rasgos más sobresalientes del

Analizando los detalles uno por uno, notamos una mezcla de elementos culturales bastantécheterogéneos, mezclasademás típica para todas las épocas tardías.

La misma construcción de fa tumba, que consiste básicamente en una cámara subterrónea y un pasillo inclinado, se encuentra desde Co. lombia hasta Chile Central, es decir a través de todo el área andina. $\sin$ que esta forma haya sido la regla en ninguna parte (Bennett, 1949, p. 48 ss.). Para Chile, esta forma ha sido descrita por Latcham (1938, p. 61) y la atribuye a la época "atacameña indígena"; según el soleos de familia Chiuchiu esta clase de sepulturas, que eran maubas típicas para la encuentran en uso hasta la época actual; las tumcontraba en gra la época incásica eran los túmulos, cuya celda se en. de tierra y vientras a ras del suelo y tapada con un amontonamiento ver estaba plenras (Latcham, 1938, p. 68). Dentro de la celda el cadáde su ajuar. Esta masión acuclillada, envuelto en sus tejidos y rodeado en el Norte de Chile "a lo sumo setenta y - Y siempre según los cálculos de R. Latchamse encuentra desde el ex años antes de la aparición de los españoles", donde habitó el así llamatomo norte del país hasta la región central, los ríos Choapa y Maipo Fsto "pueblo de los túmulos", en la región entre que ver con los de la época in túmulos aparentemente no terían nada a la época clásica de Tiahuancúsicu, sino eran anteriores (¿posteriores 
de otra manera: tendido, con las ofrendas a la cabecera y a los pies. Esta manera de sepultar se expandió por todas las provincias centrales y meridionales hasta el Canal de Chacao (Latcham, 1928, p. 133 ss.). La misma. manera de sepultar el cadáver en posición tendida o recostada, a veces con las rodillas dobladas, era la usual en la región diaguita que estaba situada entre el territorio de los atacameños y el de las tribus de Chile Central, o sea entre los ríos Copiapó y Choapa. La tumba misma era una excavación de poca profundidad en el suelo, con las dimensiones necesarias para dar cabida a un cadáver tendido, generalmente forrada con piedras lajas y tapada con el mismo material.

De este modo vemos, que la forma de las sepulturas de La Reina, aunque existiendo en todo el territorio andino del norte y centro, no era la típica $o$ exclusiva en ninguna parte de este, sino más bien la excepción. La posición del cadáver, que era la acuclillada en el Perú prehispánico y entre los atacameños, era en el caso presente la tendida, la que correspondería a las costumbres de los diaguitas, de los habitantes de Chile Central y a "algunas fases tardías de la costa" peruana. (Bennett, 1946, p. 146). De estas tres posibilidades enumeradas creo que podemos excluir de antemano a los habitantes de Chile Central, puesto que en ninguna tumba se encontró objeto o rasgo que se podría atribuir a ellos. A favor de las otras dos entidades, los diaguitas chilenos y los peruanos de la costa, habla la presencia de objetos que presentan claramente rasgos típicos incásicos y diaguitas. Por el otro lado, el único cráneo salvado, presenta rasgos parecidos a los que suelen encontrarse en territorio atacameño.

La cerámica, que se encontró en gran abundancia en las tumbas (veintinueve piezas en tumba II y más todavía en tumba $\mathrm{V}$; estas últimas se encontraban todas quebradas, debido al derrumbe del techo y no ha sido posible establecernel número exacto), pertenece a varios tipos: platos, jarros, ollas de pie, aríbalos, boles, pseudo-ápodos y ollas de cocina. Los cuatro primeros ostentan formas incásicas, mientras que los tres últimos pertenecen por su forma al área cultural chilena, tanto diaguitas (boles) como atacameña (pseudo-ápodos).

Los platos son de pequeñas dimensiones y poca profundidad $(14,5$ a $20,8 \mathrm{~cm}$. de diámetro por 4 a $5,5 \mathrm{~cm}$. de altura). Lucen un engobe en ambas caras, siendo el del exterior siempre rojo y el del interior - parte donde lleva además la decoración - rojo o blanco. Tienen un asa en está formado o por una cabecita de pájaro o por una cinta de corte rectangular alargado, que forma una especie de argolla en el borde. Has-
ta aquí no se diferencian en nada de idénticas formas encontradas en
yacimientos incásicos del Perú, forma llamada "drinking Yacimientos incásicos del Perú, forma llamada "drinking ladle" por Bingham (1930, p. 132 ss.). Pero solamente un pequeño porcentaje de estos platos se adhiere estrictamente a la forma peruana. La mayoría de ellos ostentan una variación en el asa, que es casi desconocida en cu lugar de origen, pero la cual es la forma más común en todos los yacimientos en suelo chileno, donde aparece este tipo: el asa no es formada por una argolla adjunta al borde, sino se presenta como conti- 
nuación de la pared del plato en forma de media circunferencia. En la decoración de estos platos se pueden apreciar igualmente dos tendencias. Una que es una imitación fiel de la decoración incásica, tanto en sus motivos como en su disposición, mientras que la otra se adhiere a los patrones de la cerámica diaguita. En el primer caso, el fondo blanco del interior es cruzado por una franja ancha, muchas veces reticulada, que va desde las. protuberancias hacia el asa; saliendo del centro del borde, que queda en ambos lados de ella, se encuentra una figura triangular, cuyo apex apunta hacia el centro del fondo. Los motivos son ejecutados en rojo y negro. En la variante que demuestra decoración del tipo diaguita, ésta se encuentra en forma de una franja alrededor del borde interno, dejando libre todo el fondo. Entre estos dos extremos hay toda una gama de tipos intermediarios, así por ejemplo algunos platos, con la división del campo descrito más arriba, en los cuales las figuras triangulares son las llamadas "cabezas de tigre" de la decoración diaguita. Otros ejemplares lucen engobe rojo en ambas caras y tanto motivos diaguitas como incásicos son ejecutados en color negro sobre la superficie interna roja, abandonando así el patrón tricolor a favor de uno bicolor, como se encuentra en el área atacameña y también en Chile Central.

Los jarros son pequeños vasos de 9,5 a $12,5 \mathrm{~cm}$ de altura, de cuello angosto y cuerpo subglobular con base ancha y un asa transversal arqueado en la parte superior del cuerpo. (Un ejemplar tiene el asa dispuesta verticalmente). Alrededor de los hombros, hasta el punto donde se desprende el asa, están decorados con una ancha franja de motivos escalonados y otros, ejecutados sobre el engobe blanco del cuerpo. De esta faja salen - a manera de apéndices- partes del tan típico motivo fitomorfo de la cultura incásica. Bingham (1930, p. 123) describe este motivo como un collar, pero es más probable que se trate de un desmembramiento del tan conocido motivo fitomorfo, cuando su significado original se había perdido y servía únicamente como ornamento abstracto. Mientras que la forma de los vasos se adhiere con bastante exactitud a la forma incásica, se nota otra vez en la disposición de la decoración y en los mismos elementos decorativos - aparte del mencionado motivo fitomorfo- la influencia diaguita.

Las ollas de pie, siempre sin decoración pintada, están todas cubiertas de hollín, lo que da prueba de su uso como utensilios de cocina. Su forma en nada se diferencia de la que acostumbramos encontrar on yacimientos incásicos peruanos.

De los verdaderos aríbalos se encontró un solo ejemplar. Tiene la decoración en un lado, siendo el otro cubierto de un engobe rojo. Luce además el botoncito tan típico para esta clase de alfarería y tiene una pequeña protuberancia en el labio. La decoración se compone de elementos incásicos. Los demás vasos caben bajo el título "pseudo-ápodos", acuñado por Outes (1907). y los cuales son considerados por Latcham (1938, p. 251) como un invento atacameño, cronológicamente muy anterior a la civilización incásica. La diferencia más llamativa entre los aríbalos incásicos y los pseudo-ápodos atacameños reside en la base del ceramio y en la forma de los labios; la base del aríbalo remata 
en punta, mientras que la parte inferior del pseudo-ápodo se parece a un tronco de cono invertido. $A$ veces también ha sido trabajada en punta y esta ha. sido dada vuelta hacia adentro, resultando una base anular. Así encontramos un ejemplar con base plana, cubierto en un lado del cuerpo, cuello y labio con un engobe blanco, mientras que el otro lado luce un sencillo engobe rojo. El lado blanco ha sido decorado además con fajas verticales de dibujos en las cuales aparece el típico reticulado incásico al lado de otro, igualmente típico de "cabezas de tigre" diaguita. La pieza tiene además el botón incásico en la parte superior del lado decorado y el labio ostenta dos pequeñas protuberancias. Otros ejemplares tienen la decoración en forma de una faja alrededor de los hombros, siendo el resto simplemente lucido de rojo; en uno de estos, el motivo usado es el fitomorfo tan típicamente incásico, pero cada motivo par se encuentra invertido, produciéndose así un ritmo agradable pero ilógico del punto de vista de su significado. Otra manera de decorar a estos pseudo-apodos consiste en el dibujo de un ángulo, formado por dos pares de paralelas, que convergen hacia un punto cerca del cuello. Las paralelas están unidas entre sí por cortas líneas transversales. Este motivo presenta probablemente una estilización de los cordeles que se usaban para transportar el vaso. En general podemos decir que a una forma incásica o atacameña se han aplicado indistintivamente motivos de decoración del área incásica y del diaguita. El tamaño de las piezas pertenecientes al grupo de aríbalos y pseudo-apodos varía entre 28 y $64,5 \mathrm{~cm}$. de altura.

Como ya fué dicho, las piezas estilísticamente más puras son las ollas de pie, que no se diferencian en nada de las encontradas en el Perú. Las otras ollas son todas del tipo de la cerámica doméstica, sin engobe - con excepción de una ollita en miniatura- y sin ninguna otra decoración. Todas ellas están ennegrecidas de hollín, señal de que han sido usadas para la preparación de alimentos. Son formas tan básicas y utilitarias, que no se les puede considerar como típicas para ninguna época o cultura en especial.

El último grupo de cerámica decorada son boles hemisféricos, decorados en su cara interior, sea con una faja de motivos que corre a lo largo de borde o con una serie de ángulos formados por líneas rectas que convergen hacia un punto en el centro del fondo. Ambas decoraciones son típicas para la cultura diaguita chilena y se encuentran en grandes cantidades en el área correspondiente. Otra forma, un bol de base ligeramente curva y paredes rectas con engobe rojo en la cara exterior y blanco en la interior, lucen sobre la primera una ancha faja de motivos diaguitas ejecutados en blanco, rojo y negro. Se han encontrado en una sola tumba dos de estas piezas, las cuales, por toda su ejecución, no dejan lugar a duda que provienen del valle de Elqui, centro del área diaguita, donde representan la forma más típica y más frecuente de cerámica decorada. Los boles hemisféricos oscilan entre 20 y 33 cms. de diámetro y los dos últimos entre 15 y $16,8 \mathrm{~cm}$. con una altura algo superior a $7 \mathrm{~cm}$.

Los otros objetos encontrados en el cementerio de La Reina se adhieren al patrón cultural incásico: varios queros de madera con de- 
coración incisa (en tan mal estado de conservación, que era imposible salvarlos); en uno de ellos se encontró un par de pinzas de cobre; una cabeza de maza en forma de estrella de seis puntas, que se encontró a la altura del hombro derecho de uno de los esqueletos; un plato de piedra con dos asas, sin ninguna decoración pero de artesanía perfecta (Compárese Rowe, 1946, p. 248); un topu de plata con cabeza en forma de medio círculo; láminas de metal -oro y plata- que estaban cubriendo la cábeza y cara del esqueleto y que probablemente habían estado cosidas sobre algún género.

Una excepción en este inventario de objetos incásicos forman los restos de una manopla de cobre, que fué encontrada en una tumba de Este grupo, excavada por otras personas: en territorio actual chileno, la manopla pertenece al círculo cultural diaguita y de allí irradió probablemente al área atacameña.

La -aunque somera- descripción del hallazgo de La Reina ha dejado en claro, que nos encontramos frente a una mezcla íntima de dos civilizaciones andinas, la incásica y la diaguita-chilena, con huellas de una tercera, la atacameña. No se trata de una simple superposición, de un lado a lado, de elementos culturales procedentes de diferentes civilizaciones, sino de una impregnación profunda, que ha conducido a una nueva entidad de estilo. Este hecho presupone una larga experiencia por parte de los artesanos diaguitas con las manifestaciones culturales incásicas o, viceversa, una larga familiaridad del artesano incásico con los patrones diaguitas.

El hallazgo de La Reina no es el único en el cual se ha encontrado influencia incásica en Chile. Eso sí, es el más importante en cuanto a la cantidad de material encontrado y ante todo por tratarse de un yacimiento no violado con anterioridad. Objetos de procedencia incásica se han encontrado en muchos puntos del (país, , como Arica y valles adyacentes, Caldera, Freirina, Copiapó, La Serena, San Felipe, Vailenar, Quillota, Santiago y otros más, especialmente a lo largo de los así llamados "caminos del Inca", que probablemente eran en su origen ios caminos de los atacameños, pueblo muy dado a largas excursiones a través del país y que fueron aprovechados, arreglados y prolongados por los Incas, cuando ellos ocuparon estas provincias.

Una curiosa influencia secundaria de la civilización incásica se encientra en la parte austral de Chile. Aunque no se puede decirlo con sequridad, parece más que probable, que los Incas fijaron el Río rasgos como frontera austral de su imperio. No obstante se encuentran bilidad de cultura al sur de esta línea y estos datan con toda probado traídos y difundidos tiempos de la ocupación española y habían siacompañaban andidos por los indios peruanos o del norte de Chile, que p. 226) explica las huestes españoles. Así Latcham (1928, p. 196 ss. Y presencia de motivos incásicos en la alfarería araupor los arau platería, siendo la metalurgia una industria desconocida Española mica de misno pasa más al sur todavía, con la llamada "ceráestenta tanto en forma como en decoración influencias incásicas y peruanas en general. 
Han pasado más de cuatro siglos desde el fin del imperio incásico. No obstante no ha muerto del todo, ni en provincias tan apartadas de su capital, como lo es el norte chileno. En la fiesta de Ayquina, que se celebra cada 8 de setiembre en honor de la Virgen, participa un grupo de bailarines que se llama los "hijos de Atahualpa"; en la fiesta de La Tirana, el "Rey Inca" habla a la gente, y las fechas de solsticio, especialmente la de invierno, tienen todavía gran importancia en la vida de los habitantes de los pequeños pueblos del norte, aunque el antiguo zulto del sol se esconde ahora detrás de las fechas cristianas de San Iuan y Navidad.

Resumiendo se puede decir, que la civilización incásica, en su marcha hacia el sur se ha encontrado con pueblos de un nivel cultural parecido al de ella y ha sido aceptada no sólo porque era la civilización de los conquistadores, sino también porque logró incitar la fantasía de los conquistadores, los cuales la incorporaron de tal manera que se puede hablar de una nueva época artística y cultural con caracteres propios e inconfundibles.

\section{PUBLICACIONES CITADAS EN EL TEXTO}

BENNETT, W. C.: 1946, The Archaeology of the Central Andes; Handbook of South American Indians, vol. II, pp. 61-147. Wash.

1949, Religious Structures; Handbook of South American Indians, vol. V, pp. 29-51. Wash.

BINGHAM, H.: 1930, Machu Picchu. New Haven.

LATCHAM, R. E.: 1928. Ž Prehistoria Chilena. Santiago.

1938. Arqueología de la Región Atacameña, Santiago.

OUTES, F.: 1907, Alfareria del Noroeste Argentino; Anales del Museo de La Plata, $2^{\mathrm{a}}$ serie, tomo I. La Plata.

ROWE, J. H.: 1946, Inca Culture at the Time of the Spanish Conquest; Handbook of South American Indians, vol. II, pp. 183-330. Wash. 